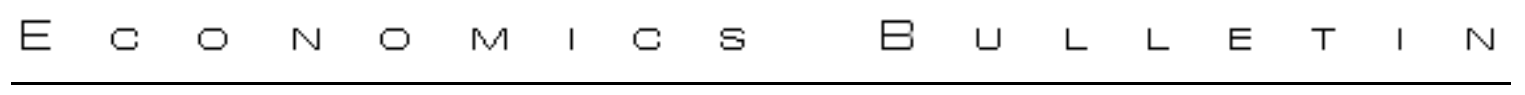

\title{
Energy Prices and Induced Technological Progress
}

\author{
Surender Kumar \\ TERI University, New Delhi, India
}

\begin{abstract}
This study measures energy price induced technological change using directional distance function for a panel data of 55 countries over the period 1974 to 2000 . The parameter estimates of directional distance function reveal the absence of neutral exogenous innovations and the presence of biased innovations either it is exogenous or energy price induced. We observe larger energy price induced technological change effects in developed countries in comparison to developing countries in the periods after first (1974), and second (1980) world oil crisis that caused substantial energy price increases. These findings concur with data that show most RDoccurs in high-income countries, particularly the US and Japan.
\end{abstract}

Citation: Kumar, Surender, (2008) "Energy Prices and Induced Technological Progress." Economics Bulletin, Vol. 15, No. 17 pp. 1-15

Submitted: September 26, 2008. Accepted: November 2, 2008.

URL: http://economicsbulletin.vanderbilt.edu/2008/volume15/EB-08030006A.pdf 


\section{Introduction}

Technological progress plays a crucial ameliorating role in reducing energy consumption for combating climate change. Energy economists often cite market based instruments such as energy taxes for encouraging energy saving technological progress. Energy policy interventions may change the constraints and incentives that affect technological change (TC). For instance, changes in current relative energy prices may induce substitution of energy by other factors of production and changes in its long-run prices may induce development of new energy saving technologies. The importance of relative prices as a stimulator of technological advancement is traceable to Hicks (1932). Theory of induced innovation helps in measuring the impact of relative prices on the direction of technological change (Hayami and Ruttan, 1971).

Technological change can be decomposed into two components- innovation and diffusion, and the transformation function ${ }^{1}$ is best suited to measure technological change (Jaffe et al. 2003). The transformation function represents 'best practice', i.e., what the economy would produce if all innovations made to date had fully diffused; therefore, the shift in transformation function captures innovations. The role of diffusion would then arise if some countries are not adopting 'best practice' and operating at points inside the transformation frontier. The movement of these countries towards the frontier can be termed as 'catch-up' effect or technological diffusion (TD). The present study tends to extend the literature on induced technological progress by measuring both innovations and diffusion.

We use directional distance function for measuring energy price induced technological change (TC). Directional distance function simultaneously seeks to expand output and contract inputs. It is particularly well suited to the task of providing a measure of technical efficiency in the full input-output space and satisfies all those properties, which are satisfied by the conventional representations of production technology.

There is considerable theoretical and empirical literature on induced innovation hypothesis. ${ }^{2}$ That literature typically analyses the inducement effect in the framework of conventional representation of production technology, such as cost, production or profit functions. Distinguishing between factor substitution and shift of transformation frontiers is problematic with the conventional representations. That is, in conventional representations the first order comparative static optimization conditions cannot be followed since the direct derivatives of the demand and supply functions with respect to prices cannot be unambiguously signed, given the presence of the cross derivatives (Celikkol and Stefanou, 1999; Paris and Caputo, 2001).

We measure TC for a sample of 55 countries over the period 1974 to 2000 using macro variables. TC is similar in nature to any investment process, as it requires time and adjustment that is not instantaneous, and the choice of technology is influenced by long-term prices. Innovations are decomposed into two parts; namely, exogenous innovations (EI) and energy price induced innovations (PII). A time trend variable is used to measure exogenous innovation. ${ }^{3}$ Similarly the inclusion of long-term energy prices as a sift factor in the transformation function

\footnotetext{
${ }^{1}$ Transformation function describes a production possibility frontier, that is, a set of combinations of inputs and outupts that are technically feasible at a point in time.

${ }^{2}$ See Hayami and Ruttan, 1971; Binswanger, 1974; Binswanger, 1978; and Thirtle and Ruttan (1987) for a summary of this literarue.

${ }^{3}$ Technological progress occurs both due to inducements and advancements in general science and technology. Therefore, a time trend is included as an argument in the transformation frontier to account for the impact of scientific innovation on the production technology (Lansink et al., 2000, p. 500, footnote 1).
} 
is used for measuring the induced innovation effect. We use oil prices as proxy for energy prices. ${ }^{4}$

The study is organized as follows: Section 2 outlines the measurement of technological change. Data and results are discussed in Section 3.. Summary and conclusions are presented in Section 4.

\section{Measurement of Technological Change}

We extend the Luenberger measure of productivity change, introduced by Chambers et al. (1996) and Chambers (2002), to a measure that also accounts for energy price induced innovations. The Luenberger productivity indicator is decomposed into two component measures: innovation and diffusion. We decompose innovation further into EI and PII. This can be illustrated through the Figure 1.

Suppose a country in the year $t$ with input-output $\left(x^{t}, y^{t}\right)$ vector is operating at point $a$, and in the year $(t+1)$ with the input-output vector $\left(x^{t+1}, y^{t+1}\right)$ is at $d$. The technologies at these two points of time are specified as $T^{t}$ and $T^{t+1}$. The shift in technology from $T^{t}$ to $T^{t+1}$ is the combination of energy price induced and exogenous innovations, i.e., shift in the production technology from $T^{t}$ to $P$ is induced by the factors such as change in relative long term energy prices and the shift from $P$ to $T^{t+l}$ is due to some external factors such as advancement in science and technology. Therefore we get

$$
\begin{aligned}
& \text { Diffusion }=(b-a)-(f-d) \\
& \text { Innovation }=0.5((f-e)+(c-b))=0.5(((f-k)+(k-e))+((c-j)+(j-b)))
\end{aligned}
$$

or

$$
\text { Innovation }=0.5((f-k)+(c-j))+0.5((k-e)+(j-b))=E I+P I I
$$

Thus technological diffusion is measured by the distance of points $a$ and $d$ from the transformation functions $T^{t}$ and $T^{t+1}$, respectively.

To measure the technological change, we use directional distance function. Directional distance function seeks to expand the desired output e.g., GDP and contract inputs such as labour, capital and energy, and inherits its properties from the production technology, T. ${ }^{5}$ More formally the function is defined as:

$$
D(x, y ; g)=\max _{\beta}\left\{\beta:\left(y+\beta \cdot g_{y}, x-\beta \cdot g_{x}\right) \in T\right\}
$$

where $T=\{(x, y): x$ can produce $y\}$, and $y=\left(y_{1}, \ldots, y_{M}\right) \in \mathfrak{R}_{+}^{M}$ and $x=\left(x_{1}, \ldots, x_{N}\right) \in \mathfrak{R}_{+}^{N}$ are output and input vectors, respectively. The solution, $\beta^{*}$ gives the maximum expansion and contraction of outputs and inputs, respectively. The vector $g=\left(g_{y},-g_{x}\right)$ specifies in which direction an output-input vector, $(y, x) \in T$ is scaled so as to reach the boundary of the technology frontier at $\left(y+\beta^{*} \cdot g_{y}, x-\beta^{*} \cdot g_{x}\right) \in T$, where $\beta^{*}=D(x, y ; g)$. This means that the producer becomes more technically efficient when simultaneously increasing outputs and decreasing inputs. The function takes the value of zero for technically efficient output-input

\footnotetext{
${ }^{4}$ In the energy consumption oil accounts for most of the consumption of hydrocarbons, although the use of natural gas has risen in the past decades or so and there is high positive correlation between oil and natural gas prices. Moreover, oil accounts for about 35\% of global annual use of primary energy, with much of that oil coming from politically unstable regions (Gallagher et al., 2006), therefore, it is assumed that it is oil price volatility which induces technological progress which is energy saving.

${ }^{5}$ For properties of directional distance function see, Fare et al. (2005)
} 
vectors on the boundary of $T$ whereas positive values apply to inefficient output vectors below the boundary. The higher the value the more inefficient is the input-output vector, i.e., the directional distance function is a measure of technical inefficiency.

We parameterize the directional distance function in quadratic form hence; it is possible to apply Diewert's (1976) Quadratic Identity Lemma. ${ }^{6}$ Using this identity, changes in the directional distance function from one period to the next can be written as:

$$
\begin{aligned}
& \left(D^{t}-D^{t+1}\right)=0.5\left[\frac{\partial D^{t}}{\partial y}+\frac{\partial D^{t+1}}{\partial y}\right] \cdot\left(y^{t+1}-y^{t}\right)+0.5 \sum_{n=1}^{3}\left[\frac{\partial D^{t}}{\partial x_{n}}+\frac{\partial D^{t+1}}{\partial x_{n}}\right] \cdot\left(x_{n}^{t+1}-x_{n}^{t}\right) \\
& +0.5\left[\frac{\partial D^{t+1}}{\partial t}+\frac{\partial D^{t}}{\partial t}\right]+0.5\left[\frac{\partial D^{t+1}}{\partial \bar{r}}+\frac{\partial D^{t}}{\partial \bar{r}}\right] \cdot\left(\bar{r}^{t}-\bar{r}^{t+1}\right)
\end{aligned}
$$

where $D^{t}$ is short for $D\left(x^{t}, y^{t} ; g, t, \bar{r}\right)$. Technological change (TC) can be defined as:

$$
T C=-0.5\left[\frac{-\partial D^{t+1}}{\partial y}+\frac{-\partial D^{t}}{\partial y}\right] \cdot\left(y^{t+1}-y^{t}\right)+0.5 \sum_{n=1}^{3}\left[\frac{\partial D^{t+1}}{\partial x_{n}}+\frac{\partial D^{t}}{\partial x_{n}}\right] \cdot\left(x_{n}^{t+1}-x_{n}^{t}\right)
$$

Technological change can be broadly defined as the difference of the weighted average rates of change in outputs and inputs, where the weights are derivatives of directional distance function with respect to (negative) output and (positive) inputs respectively. Rearranging equation (4), TC can be decomposed as:

$$
T C=\underbrace{\left(D^{t+1}-D^{t}\right)}_{\text {Diffusion }}-\underbrace{0.5\left[\frac{\partial D^{t+1}}{\partial t}+\frac{\partial D^{t}}{\partial t}\right]}_{E I}-\underbrace{0.5\left[\frac{\partial D^{t+1}}{\partial \bar{r}}+\frac{\partial D^{t}}{\partial \bar{r}}\right] \cdot\left(\bar{r}^{t+1}-\bar{r}^{t}\right)}_{P I I}
$$

Equation (5) provides a meaningful decomposition of TC into diffusion, exogenous innovations (EI) and energy price induced innovations (PII), respectively. Negative values of the derivatives of directional distance function with respect to time-trend and long-run energy prices imply positive change in EI and PII respectively. Therefore, the negative value of each components of productivity index implies positive change in technological change (TC). ${ }^{7}$

\section{Data and Results}

For measuring energy price induced technological change, the resource constraint consists of the net fixed standardized capital stock, labour force, measured by the number of employed workers and energy use measured in kilotons (kt) of oil equivalent. Real GDP (adjusted for 1996 prices) measured in \$PPP is taken as an indicator of output. Data on the capital stock, labor, and real GDP are compiled from a recent data set in Marquetti (2002). World Development Indicators (World Bank) is the source for energy use. Crude oil prices, currency exchange rates and country specific consumer price indices are complied from International Financial Statistics (IMF) to create country specific indices of relative oil prices as a proxy for country specific energy prices. The annual panel data set includes 55 countries $^{8}$, a mix of developed and

\footnotetext{
${ }^{6}$ Orea (2002) used the quadratic identity lemma for parametric decomposition of Malmquist productivity index using output distnance function.

${ }^{7}$ In the discussion of results, for the sake of convention we have multiplied each of the component by minus one.

${ }^{8}$ We have grouped all the countries in two categories according to World Bank Classification on the basis of per capita incom: develoing and developed countries. The countries included in the study are: CAMEROON, COTE d'IVOIRE, EGYPT, EL SALVADOR, ETHIOPIA, GHANA, GUATEMALA, HONDURAS, INDIA, KENYA, NIGERIA, PAKISTAN, PARAGUAY, PHILIPPINES, SENEGAL, SRI LANKA, SYRIA, TANZANIA, TOGO, COLOMBIA, COSTA RICA, DOMINICAN REP., ECUADOR, GABON, INDONESIA, JAMAICA, JORDAN,
} 
developing countries for the period 1974-2000. The choice of countries and study period is constrained on the availability of the required information. The period of study starts just after the first oil shock.

The choice of oil price variables is difficult and, country specific oil prices oil prices have been influenced by price-controls, high and varying taxes on petroleum products, exchange rate fluctuations and country specific price index variations. Most of the empirical literature analyzing the effect of oil price shocks use either the \$US world price of oil as a common indicator of the world market disturbances that affect all countries (see, e.g., Burbidge \& Harrison, 1984) or this world oil price converted into each respective country's currency by means of the market exchange rate and adjusted by the domestic inflation (see, e.g. Mork et al., 1994 for OECD countries or Cunado and Gracia, 2005 for Asian countries). The main difference between the two variables is that only the second one takes into account the differences in the oil price that each of the countries faces due to its exchange rate fluctuations and its inflation levels. In the present study we use the second kind of oil price indices for analysis. The oil price indices are created by taking the 1970 as the base year.

The notion of long-run prices serving as a stimulating factor to innovate is a critical component of the price-induced innovation model. Changes in current prices induce factor substitution where changes in long-run prices induce the development of new technologies leading to the shift of the technology frontier. Therefore, it is important to model long-run prices which depend on current and past price information as arguments in the production technology frontier to separate scarcity responses from biased PII. Past country specific prices of energy is included in the country-specific frontier function to measure PII and is generated as a 3-year moving average of past energy prices. The choice of 3-year moving average is based on the assumption that firms use most recent years as having the greatest information content (Lansink et al., 2000). Such kind of the choice of long-term energy prices is also consistent with an adaptive expectation model of prices; in which expected future prices depend on a weighted average of past prices (Popp, 2002).

For the measurement of exogenous and energy price induced innovations, following Färe et al. (2005), we econometrically estimate directional distance function using normalized values of inputs and outputs. ${ }^{9}$ This normalization implies that $(x, y)=(1,1)$ for a hypothetical country that uses mean inputs and produces mean output.

We estimated four specifications of directional distance function. In specification 1, we estimate the directional distance function only in input-output vectors, in specification 2 , we include the trend variable as the shift parameter and in specification 3 there are two shift parameters: time trend and long run relative energy prices. As noted above the sample consists 55 countries, we grouped the countries in two groups: developing and developed countries, and in the estimation we included the group dummy also (specification 4). The selection of model is done on the basis of log-likelihood ratio (LR) test. Table 1 provides the LR test statistics. On the basis of LR test statistics, specification 4 is finally selected for further analysis.

Table 2 provides the parameters estimate of directional distance function for specification 4. Most of the ML coefficients are accurately estimated. Technical inefficiency is correctly

MOROCCO, PERU, SOUTH AFRICA, TRINIDAD \& TOBAGO, URUGUAY, VENEZUELA, ARGENTINA, CHILE, IRAN, MALAYSIA, MEXICO, THAILAND, TURKEY, AUSTRALIA, BOLIVIA, CANADA, DENMARK, GREECE, ICELAND, ISRAEL, JAPAN, KOREA REP. OF, NEW ZELAND, NORWAY, SWEDEN, SWITZERLAND, UNITED KINGDOM, USA.

${ }^{9}$ We normalized the data for each output and each input by their mean values before estimation. 
identified within the composed error term: (i) the LR test on the one-sided error is highly significant; (ii) the share of technical inefficiency in total variance is high, i.e., 93 percent and (iii) it appears to have an exponential distribution with $\theta=15.45$.

A first look at the production technology parameters in Table 2 indicates that the first order coefficients on output and inputs have expected signs regarding economic behavior. Looking at the signs of second order parameters, it appears that they involve interesting results too; however, require a more detailed analysis to measure their final influence. The resulting distance functions satisfy the regularity conditions of convexity on inputs and concavity on outputs for majority of observations. ${ }^{10}$

The parameters associated with time-trend and long-term energy price variables are of specific interest. Negative parameters indicate positive TC; a positive parameter indicates negative TC. The LR test statistics on these parameters allows us to reject the null hypotheses of no exogenous (EI) or energy price induced innovations (PII) (Table 2). We find absence of neutral EI as the coefficients $\gamma_{1}$ is statistically insignificant although it has required sign, but the presence of biased or embodied EI as the coefficients of interaction terms between time-trend \& output and time-trend \& inputs are statistically significant. The coefficient $\gamma_{2}$ is positive and statistically significant indicating regressive neutral PII. This observation is consistent with the literature on inverse relationship between oil prices and GDP growth. This is due to the classic supply-side effect according to which rising oil prices are indicative of the reduced availability of a basic input to production, leading to a reduction of potential output. Consequently, there is a rise in cost of production, and the growth of output and productivity are slowed. ${ }^{11}$ But the coefficients of interaction terms between output \& energy prices, and inputs \& energy prices indicate progressive embodied PII.

Moreover, the results reveal that TC varies considerably between countries. For instance, India in developing countries and Japan and USA in developed countries observe larger technological change effects (Figures 3 through 5). One explanation for this could be that the functional form used is only a local approximation, and the countries that differ significantly from the rest may be assigned extreme TC. ${ }^{12}$

The components of technological change are presented in Table A1. The world witnessed technological progress increasing by 0.1 percent per annum and it is attributed to the growth of exogenous innovations since the technological diffusion effect was negative of the magnitude of -0.1 percent per annum.

During the study period, 25 countries observed positive TC and India experienced the highest growth rate of the magnitude of 3.72 percent per annum, and about 97 percent of it can be attributed to innovations. In the technological progress, India is followed by Japan (2.21\%), USA $(2.16 \%)$ and United Kingdom (1.18\%). Korea and Nigeria experienced negative technological change of the magnitude of 1.66 percent and 1.07 percent per annum respectively.

The technological diffusion or catch-up effect is negligible across the groups, although it is positive in the developed countries and negative in developing countries. In the sample of 55 countries, Japan observed the highest technological diffusion effect of the magnitude of about

\footnotetext{
${ }^{10}$ We find that the monotonicity conditions with respect to output is satisfied by all the observations, and with respect to inputs: labour, capital and energy these conditions are satisfied by $98.18 \%, 100 \%$, and $100 \%$ observations respectiverly.

${ }^{11}$ see among others, Barro, 1984; Brown and Yücel, 1999; Abel and Bernanke, 2001.

${ }^{12}$ The size of these economies is quite large in comparison to other sample countries and they may be outlier in the sample.
} 
2.15 percent per year followed by the USA of the magnitude of 1.09 percent. On the other hand, Korea and Nigeria witnessed decline in catch-up effect of the magnitude of 1.85 and 1.52 percent per annum respectively, which explain the decline of technological change in these countries. Out of 55 countries, 11 countries tried to catch the world frontier and 44 countries observed negative catch-up effect.

Innovations are decomposed into two categories: exogenous and energy price induced. It is found that the developed countries witnessed higher exogenous innovations (EI) in comparison to developing countries and the gap between the groups in the growth of EI has narrow down over time (Figure 2). Fifty-four countries witnessed exogenous innovations (EI) and India observed the highest growth rate in EI of the magnitude of about 3.4 percent per annum followed by USA $(2.96 \%)$. Only Gabon experienced the decline in EI. This implies that although innovations have contributed positively to growth for most countries, the pattern is very dissimilar and developed countries have benefited more from exogenous innovations than developing countries. ${ }^{13}$

Figure 2 reveals that developed countries observe substantial energy price induced innovations (PII) when the long-term oil prices were rising, although the growth rate of PII is much volatile in these countries. In the developing countries the magnitude of PII is negligible and is not associated with the long-term changes in energy prices. This finding is consistent with the given level of energy consumption in the concerned economies. In the developed economies the per capita as well aggregate energy consumption is too high in comparison to developing economies so the expected magnitude of PII is expected to be higher. The developed countries account for more than half of the world total final consumption of energy (IEA, 2006). During the study period 22 countries observed outward shift in production frontier due to change in long-term oil prices, although the magnitude of progress was negligible.

To understand the implications of long-term oil prices the obvious way is to analyze the country specific results. But due to space constraint, we present the analysis of results for three major economies, viz., USA, Japan and India; the first two are developed and the third one is a major developing economy. We consider these three economies for further analysis because of their size and aggregate consumption of energy. Japan and the US together account for about 75 percent of the estimated public sector spending in the area of energy research, development and demonstration (ERD\&D) by International Energy Agency (IEA) countries (Gallagher et al., 2006). Although there are no systematic and detailed data on public ERD\&D spending in developing countries, the spending in India is fairly large. India spent the equivalent of about 0.9 billion 2000 PPP\$ in 1996-97 (Sagar, 2002). The results of these three countries are presented in Figures 3 through 5.

In all the three economies, we observe a stable growth path in the exogenous innovations (EI). The US economy experienced the exogenous innovations of the magnitude of about 3 percent per annum and it was 3.4 percent per annum for India. The annual growth rate of EI in Japan was 0.76 percent. The path of technological diffusion is more volatile in USA in comparison Japan and India. On average the contribution of the diffusion in the technological change is negligible; however all these three economies observed positive change in catch-up effect. Technological progress in Japan can be attributed to mainly technological diffusion effect, whereas in USA it is the function of both technological diffusion and exogenous innovations. In India, technological progress can be attributed mainly to exogenous innovations.

\footnotetext{
${ }^{13}$ The similar kind of trend is obsreved by Kumar and Russell (2002) using a sample of 55 countries for the period of 1965-1990. The countries taken in the studies are different.
} 
The annual growth path of energy price induced innovations (PII) is of particular interest. Figures 3 through 5 show that the path of PII is very volatile and it is consistent with the changes in long-term oil prices. All the three countries observed high growth rate in PII when the oil prices were rising and decline in PII when oil prices were declining. It is observed that the growth rate was highest during the period when long-term oil prices were at peak. This finding is consistent with the expenditure in ERD\&D area in the USA and Japan. Public ERD\&D in OECD countries showed a significant upward spike in the wake of the oil crises of the 1970s (Gallagher et al. 2006).

Moreover, it is also observed that the growth rate of energy price induced innovations was higher in USA relative to Japan. This finding is consistent with the dependence of the countries on imported oil and structural changes in energy consumption in the economies (Ono, 2005).

During the study period, India observed positive growth in energy price induced innovations during 1970s and 1980s when the oil prices were at peak and then positive changes in PII during 1995-1997 and in 2000 (Figure 5), although the magnitude of PII was much lower in India in comparison to USA and Japan.

\section{Summary and Conclusions}

Global climate change, to a large extent, is linked to the energy consumption. The reduction in energy consumption is possible with the innovations and diffusions of energy saving technologies. In this study, we have applied an analytical framework, developed by Robert Chambers and others, for estimating energy price-induced and exogenous technological change. A distinguishing feature of this framework is that it provides several peace of information simultaneously: it describes the structure of production technology; it provides a measure of technological diffusion effect; and it provides the direction and pace of energy price induced as well exogenous innovations.

Application of the analytical framework to the macroeconomic data yields several important findings. First, the parameter estimates of directional distance function reveal the absence of neutral EI and the presence of biased innovations either it is EI or PII. Second, the study provides an interesting descriptive look at innovations and diffusion across a wide range of countries. Third, in developed countries we observe larger PII in comparison to developing countries in the periods after first (1974), and second (1980) world oil crisis that caused substantial energy price increases. The time pattern of the PII effect in high-income countries also seems consistent with the economic theory and data that show most R\&D activities occurs in high-income countries, particularly in the US and Japan.

\section{References}

Abel, A.B. and Bernanke, B.S. (2001), Macroeconomics, Addison Wesely Longman Inc. Barro, R.J. (1984) Macroeconomics, John Wiley \& Sons

Binswanger, H.P. (1978), 'Measured biases of technical change: the United States', in H.P. Binswanger and V.W. Ruttan, eds., Induced Innovation: Technology, Institutions, and Development, Baltimore MD: John Hopkins University Press, 215-242

Biswanger, H.P. (1974), 'The measurement of technical change biases with many factors of production', American Economic Review 64, 964-976

Brown, S.P.A. and Yücel, M.K. (1999), 'Energy prices and U.S. aggregate economic activity', Federal Reserve Bank of Dallas Economic Review, 16-53 
Burbidge, J. and Harrison, A. (1984), 'Testing for the effects of oil price rises using vector autoregression', International Economic Review 25, 459-484

Celikkol, P., and Stefanou, S. (1999), 'Measuring the impact of price induced innovation on technological progress: Application to the U.S. food processing and distribution sector', Journal of Productivity Analysis 12, 135-151

Chambers R.G. (2002), 'Exact nonradial input, output and productivity measurement', Economic Theory 20, 751-765

Chambers, R.G., Chung, Y., and Färe, R. (1996), 'Benefit and distance functions', Journal of Economic Theory 70, 407-419

Diewert, W. E. (1976), 'Exact and superlative index numbers', Journal of Econometrics 4, 115145

Färe, R., Grosskopf, S., Noh, D., and Weber, W. (2005), 'Characteristics of a polluting technology: theory and practice', Journal of Econometrics 126, 469-492

Gallagher, K. S., Holdren, J. P. and Sagar, A. D. (2006), 'Energy-Technology Innovation', Annual Review of Environment and Resource 31: 193-237

Hayami, Y., and Ruttan, V.W. (1971), Agricultural Development: An International Perspective, Baltimore MD: John Hopkins University Press

Hicks, J.R. (1932) The Theory of Wages, New York: St. Martins

Jaffe, A. B., Newell, R. G., and Stavins, R. N. (2003), 'Technological change and the environment' in K. G. Màler and J. Vincent, ed., Handbook of Environmental Economics, Vol. 1, North-Holland, pp 461-516

Kumar, S. and Russell, R. R. (2002), 'Technological change, technological catch-up, and capital deepening: relative contributions to growth and convergence', American Economic Review 92: 527-548

Lansink, A.O., Silva, E., and Stefanou, S. (2000), 'Decomposing productivity growth allowing efficiency gains and price-induced technical progress', European Review of Agricultural Economics 27(4), 497-518

Marquetti, Adalmir, 2002. Extended Penn World Tables 2.0 Data set. Available at http://homepage.newschool.edu/ foleyd/epwt

Mork, K.A. (1994), 'Business cycles and the oil market', The Energy Journal 15, 15-38

Ono, Mitsuhito (2005), 'Rising crude oil prices affect the Japanese economy', Economic Research Department. Available at http://www.jetro.go.jp/en/market/trend/special/pdf/jem0406-1e.pdf

Orea, L. (2002), 'Parametric decomposition of a generalized Malmquist productivity index', Journal of Productivity Analysis 18, 5-22

Paris, Q., and Caputo, M.R., (2001), 'Price-induced technical progress and comparative statics', Economics Bulletin 15(8), 1-8

Popp, D. (2002), 'Induced innovation and energy prices', American Economic Review 92: 160180

Sagar, A. D. (2002), 'India's energy and energy R\&D landscape: a brief overview', Belfer Center for Science and International Affairs Working Paper 2002-08, Energy Technology Innovation Project, Harvard University.

Thirtle, C.G., and Ruttan, V.W. (1987), 'The role of demand and supply in the generation and diffusion of technical change', in F. M. Scherer, ed., Fundamentals of Pure and Applied Economics, vol. 21 in the Economics and Technological Change Section, New York: Harwood Academic Publishers 
Table 1: Tests of Hypotheses for Functional Form of Directional Distance Function

\begin{tabular}{|l|l|l|l|}
\hline Null Hypothesis & $\begin{array}{l}\text { Log Likelihood } \\
\text { Ratio Test } \\
\text { Statistics }(\lambda)\end{array}$ & Critical $\chi^{2}$ & $\begin{array}{l}\text { Decision Value at 5 } \\
\text { percent }\end{array}$ \\
\hline $\mathrm{H}_{0}: \gamma_{1}=\gamma_{11}=\eta_{11}=\eta_{21}=\eta_{31}=\mu_{1}=0$ & 771.08 & 12.592 & Reject \\
\hline $\mathrm{H}_{0}: \gamma_{2}=\gamma_{22}=\eta_{12}=\eta_{22}=\eta_{32}=\mu_{2}=\phi=0$ & 167.51 & 14.067 & Reject \\
\hline $\mathrm{H}_{0}: \psi=0$ & 136.186 & 3.84 & Reject \\
\hline
\end{tabular}

$\lambda=-2\left\{\log \left(\operatorname{Likelihood}\left(\mathrm{H}_{0}\right)-\log \left(\operatorname{Likelihood}\left(\mathrm{H}_{1}\right)\right\}\right.\right.$

Table 2: Parameter Estimates of Mean Normalized Directional Distance Function

\begin{tabular}{|c|c|c|c|c|c|}
\hline $\begin{array}{ll}\text { Name of } \\
\text { Variables/para } \\
\text { meters }\end{array}$ & Coefficient & t-Statistics & $\begin{array}{l}\text { Name of } \\
\text { Variables/para } \\
\text { meters }\end{array}$ & Coefficient & t-Statistics \\
\hline Constant $\left(\alpha_{0}\right)$ & $-0.0244^{*}$ & -4.0350 & Y.X ${ }_{3}\left(\delta_{31}\right)$ & $0.0028 *$ & 2.8150 \\
\hline $\mathrm{Y}\left(\beta_{1}\right)$ & $-0.4520^{*}$ & -203.2570 & Y.t $\left(\mu_{1}\right)$ & -0.0001 & -0.5520 \\
\hline $\mathrm{X}_{1}\left(\alpha_{1}\right)$ & $0.0843^{*}$ & 17.6290 & Y. $\bar{r}\left(\mu_{2}\right)$ & $-0.0048^{*}$ & -4.6180 \\
\hline$X_{2}\left(\alpha_{2}\right)$ & $\underline{0.2984}$ & & $0.5 \mathrm{X}_{1} \cdot \mathrm{X}_{2}\left(\alpha_{12}\right)$ & 0.0077 & \\
\hline $\mathrm{X}_{3}\left(\alpha_{3}\right)$ & $0.1653 *$ & 16.3960 & $0.5 \mathrm{X}_{1} \cdot \mathrm{X}_{3}\left(\alpha_{13}\right)$ & $0.0199 *$ & 3.7830 \\
\hline $\mathrm{T}\left(\gamma_{1}\right)$ & -0.0009 & -1.3860 & $0.5 X_{2} \cdot X_{3}\left(\alpha_{23}\right)$ & 0.0084 & \\
\hline $\bar{r}\left(\gamma_{2}\right)$ & $0.0116^{*}$ & 2.5960 & $X_{1} . t\left(\eta_{11}\right)$ & $-0.0011^{*}$ & -6.2660 \\
\hline $\mathrm{G}(\psi)$ & $0.0312 *$ & 8.1070 & $\mathrm{X}_{1} \cdot \bar{r}\left(\eta_{21}\right)$ & -0.0025 & -0.9400 \\
\hline $0.5 \mathrm{Y}^{2}\left(\beta_{2}\right)$ & $0.0074 *$ & 12.2950 & $X_{2} \cdot t\left(\eta_{31}\right)$ & 0.0010 & \\
\hline $0.5 \mathrm{X}_{1}^{2}\left(\alpha_{11}\right)$ & $-0.0179 *$ & -19.0680 & $\mathrm{X}_{2} \cdot \bar{r}\left(\eta_{12}\right)$ & -0.0055 & \\
\hline $0.5 \mathrm{X}_{2}^{2}\left(\alpha_{22}\right)$ & -0.0213 & & $X_{3 . t}\left(\eta_{22}\right)$ & 0.0001 & 0.2370 \\
\hline $0.5 \mathrm{X}_{3}^{2}\left(\alpha_{33}\right)$ & $-0.0255^{*}$ & -12.4080 & $\mathrm{X}_{3} \cdot \bar{r}\left(\eta_{23}\right)$ & $0.0032 * * *$ & 1.6350 \\
\hline $0.5 \mathrm{t}^{2}\left(\gamma_{11}\right)$ & $0.0001 * *$ & 2.4780 & t. $\bar{r}(\phi)$ & -0.0003 & -1.0230 \\
\hline $0.5 \bar{r}^{2}\left(\gamma_{22}\right)$ & -0.0014 & -1.4360 & $\theta$ & $15.4473 *$ & 39.731 \\
\hline Y.X.X $\left(\delta_{11}\right)$ & $0.0097 *$ & 14.3840 & $\sigma_{\mathrm{v}}$ & $0.0172 *$ & 15.862 \\
\hline $\mathrm{Y} . \mathrm{X}_{2}\left(\delta_{21}\right)$ & -0.0051 & & $\begin{array}{l}\text { Log likelihood } \\
\text { function }\end{array}$ & 2233.901 & \\
\hline
\end{tabular}

Note: Underlined parameters are calculated by applying the translation property of the directional distance function. Number of observation: 1485. Y: GDP, X1: labour, X2: Capital, X3: Energy.

$*, * *, * * *$ implies level of significance at $1 \%, 5 \%$ and $10 \%$ respectively. 


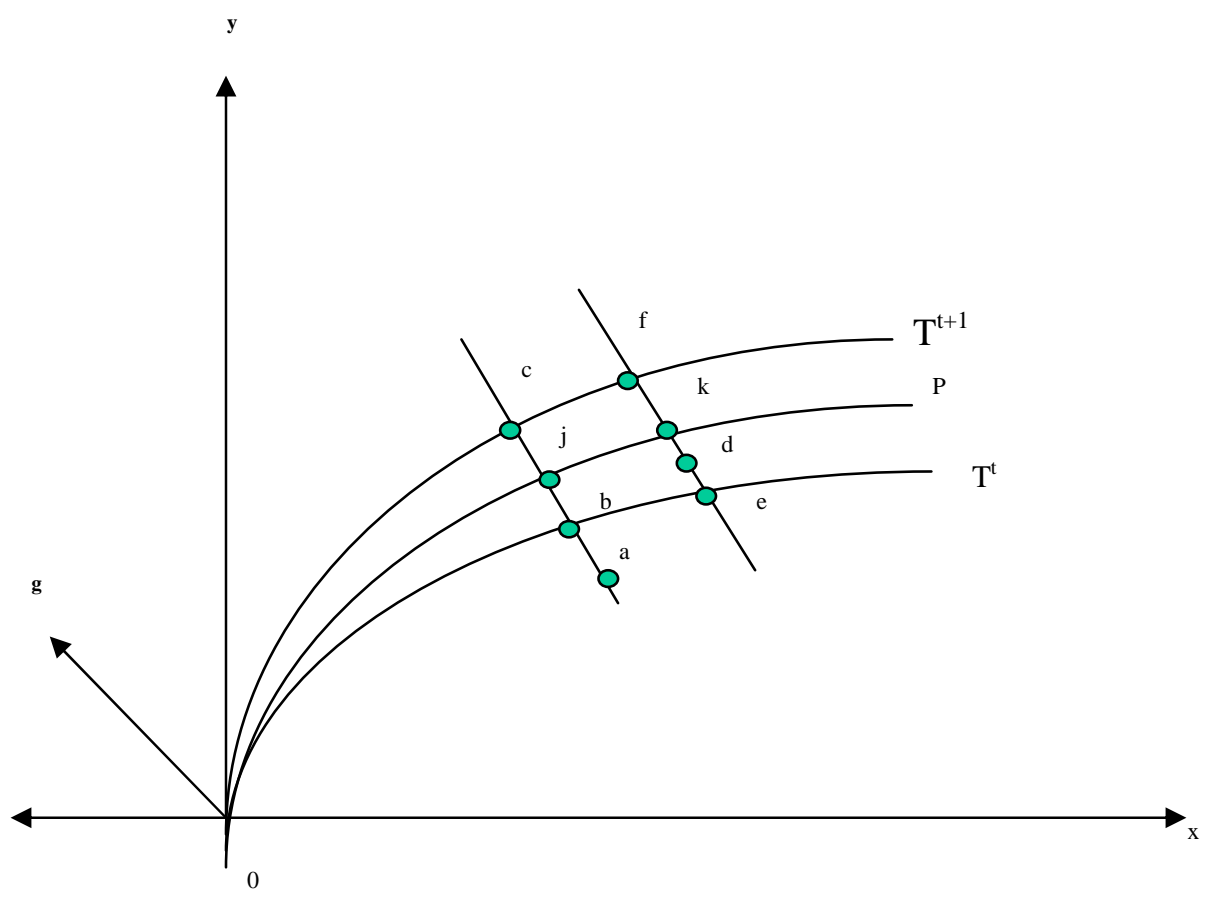

Figure 1: Luenberger Productivity Indicators

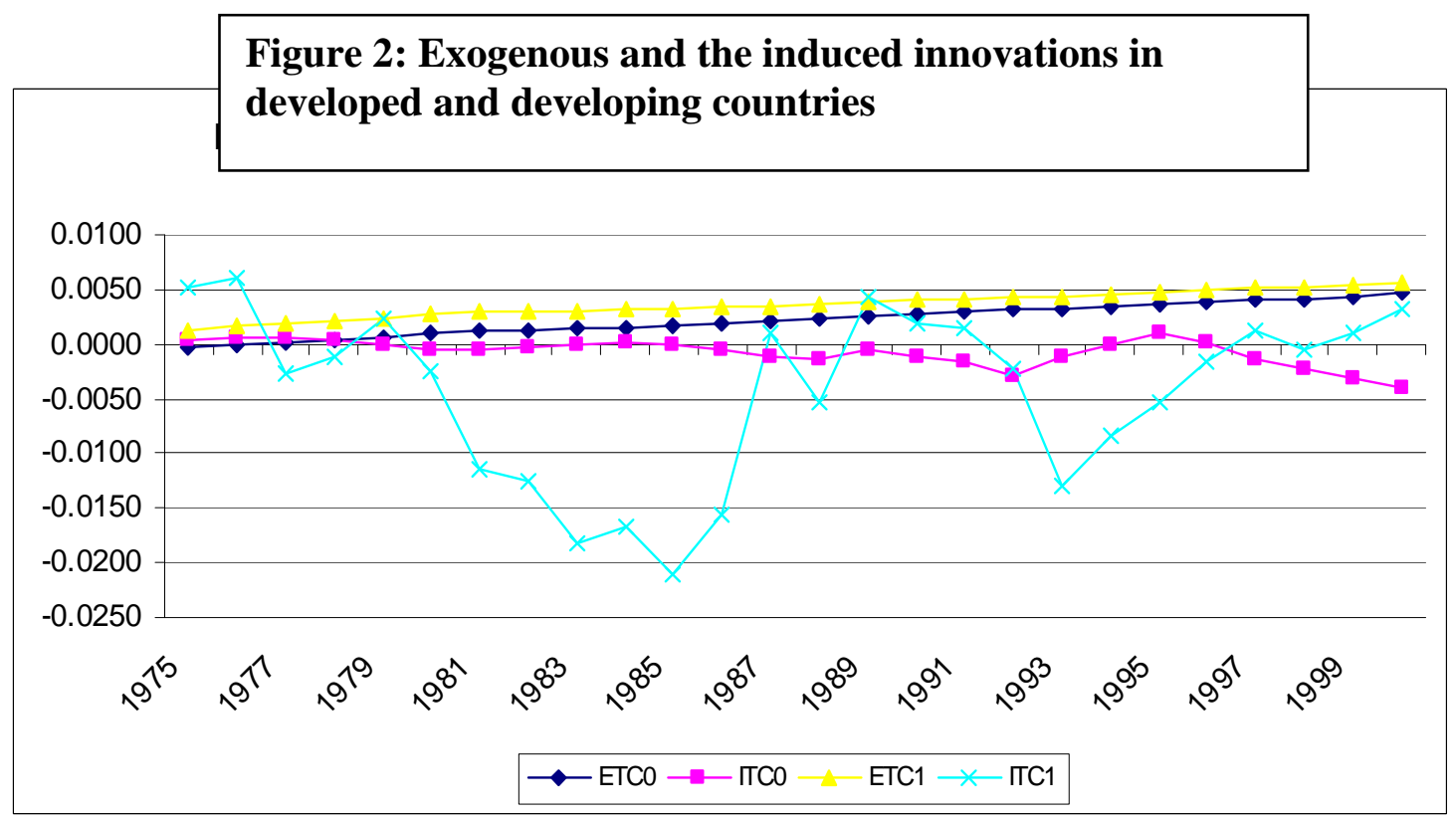

Note: ETC0: exogenous innovations in developing countries; ITC0: the induced innovations in developing countries; ETC1: exogenous innovations in developed countries; and ITC1: the induced innovations in developed countries 


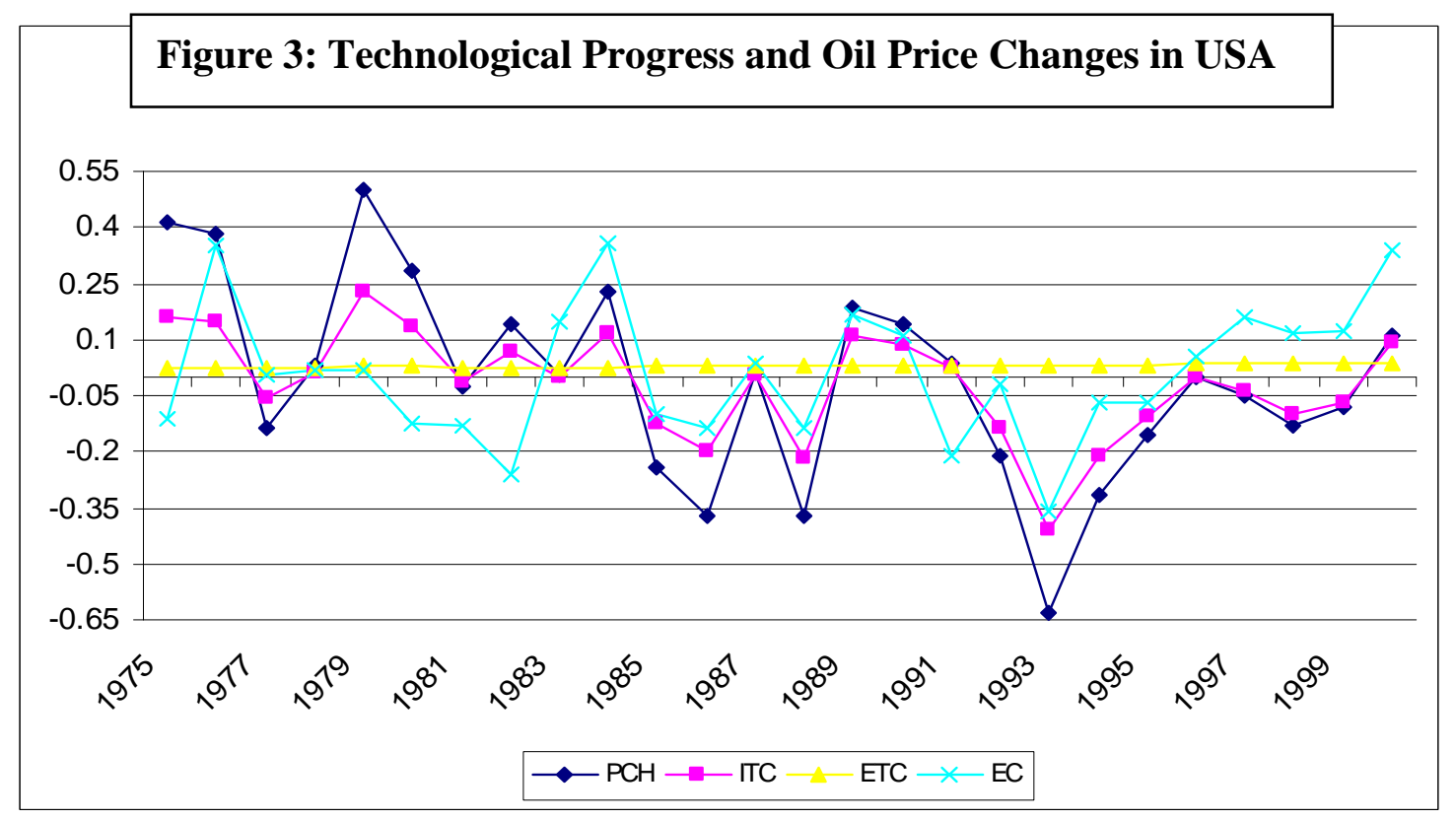

Note: PCH: long-term oil price changes, ITC: the induced innovations, ETC: exogenous innovations, and EC: technological diffusion.

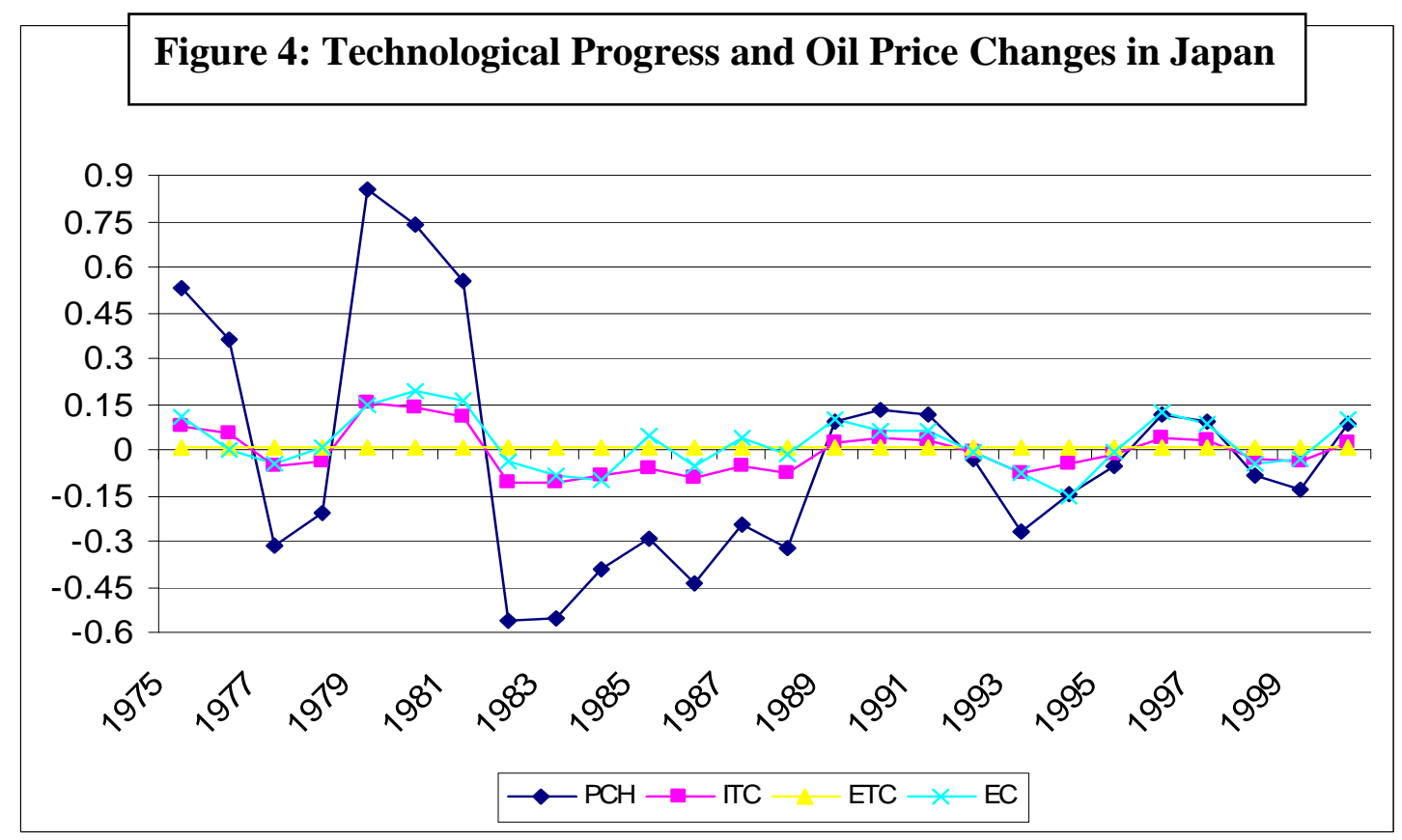

Note: PCH: long-term oil price changes, ITC: the induced innovations, ETC: exogenous innovations, and EC: technological diffusion. 


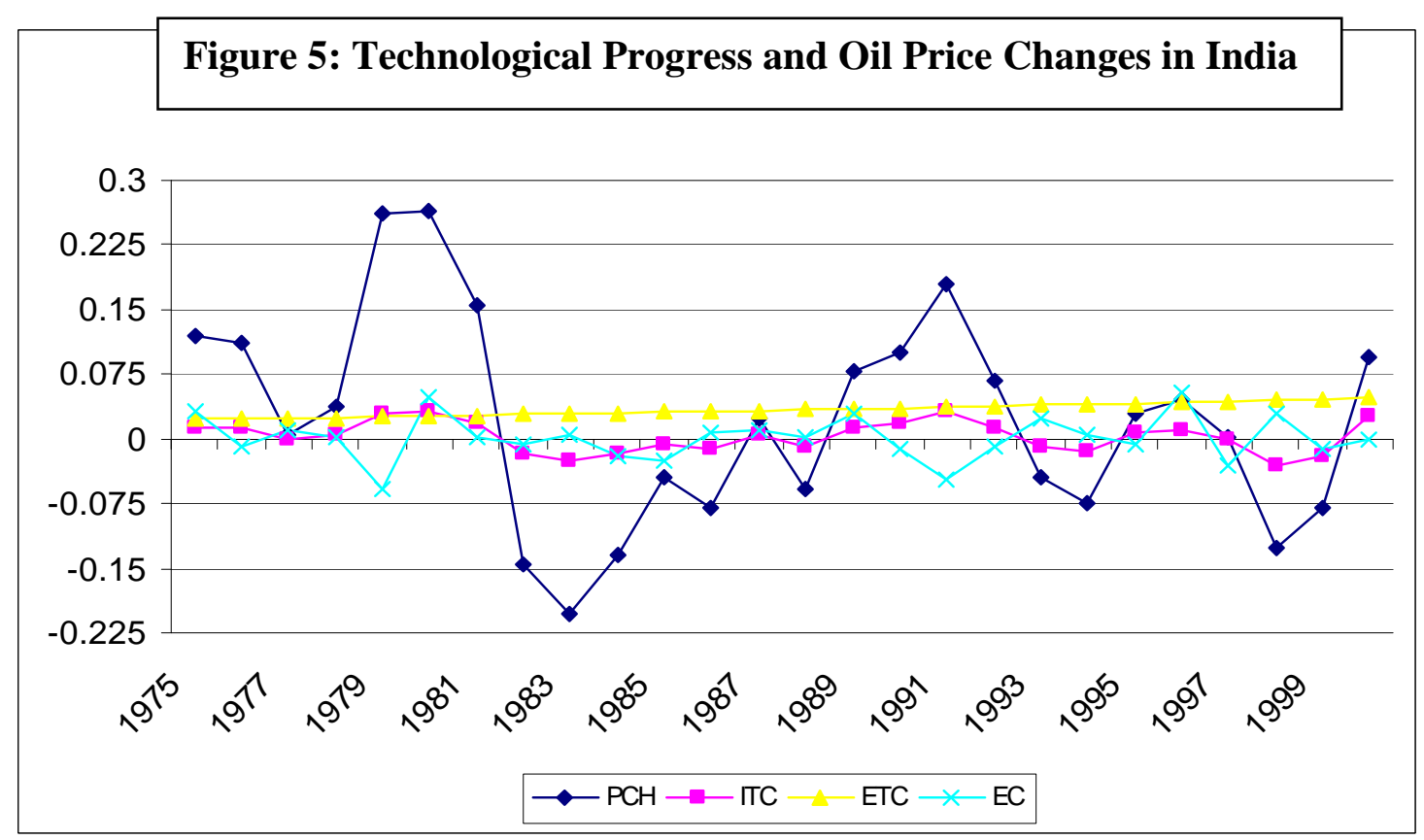

Note: PCH: long-term oil price changes, ITC: the induced innovations, ETC: exogenous innovations, and EC: technological diffusion. 


\section{Annexure}

Table A1: Average Annual Values of Luenberger Productivity Indicators

\begin{tabular}{|c|c|c|c|c|c|c|}
\hline Country & INEFF & TD & EI & PII & EI+PII & $\mathrm{TC}$ \\
\hline ARGENTINA & 0.0122 & -0.0001 & 0.0025 & 0.0006 & 0.0031 & 0.0030 \\
\hline AUSTRALIA & 0.1003 & -0.0009 & 0.0014 & 0.0002 & 0.0016 & 0.0007 \\
\hline BOLIVIA & 0.0290 & -0.0002 & 0.0005 & 0.0000 & 0.0005 & 0.0003 \\
\hline CANADA & 0.3174 & -0.0095 & 0.0028 & 0.0003 & 0.0031 & -0.0064 \\
\hline SWITZERLAND & 0.0363 & -0.0005 & 0.0006 & 0.0001 & 0.0007 & 0.0002 \\
\hline CHILE & 0.0215 & -0.0006 & 0.0007 & 0.0001 & 0.0008 & 0.0002 \\
\hline COTE d'IVOIRE & 0.0307 & -0.0009 & 0.0005 & -0.0002 & 0.0003 & -0.0006 \\
\hline CAMEROON & 0.0342 & -0.0010 & 0.0005 & -0.0002 & 0.0003 & -0.0007 \\
\hline COLOMBIA & 0.0113 & -0.0003 & 0.0017 & -0.0001 & 0.0015 & 0.0012 \\
\hline COSTA RICA & 0.0264 & -0.0002 & 0.0002 & -0.0001 & 0.0000 & -0.0002 \\
\hline DENMARK & 0.0210 & 0.0006 & 0.0006 & 0.0001 & 0.0006 & 0.0012 \\
\hline DOMINICAN REP. & 0.0274 & 0.0000 & 0.0003 & -0.0001 & 0.0001 & 0.0001 \\
\hline$\overline{\text { ECUADOR }}$ & 0.0313 & -0.0010 & 0.0003 & -0.0005 & -0.0001 & -0.0011 \\
\hline EGYPT & 0.0112 & 0.0003 & 0.0019 & -0.0002 & 0.0017 & 0.0021 \\
\hline ETHIOPIA & 0.1085 & -0.0041 & 0.0020 & -0.0003 & 0.0017 & -0.0024 \\
\hline GABON & 0.0244 & -0.0002 & 0.0000 & -0.0004 & -0.0004 & -0.0006 \\
\hline UNITED KINGDOM & 0.0542 & 0.0070 & 0.0050 & -0.0003 & 0.0047 & 0.0118 \\
\hline GHANA & 0.0401 & -0.0016 & 0.0005 & -0.0005 & 0.0000 & -0.0017 \\
\hline GREECE & 0.0248 & 0.0003 & 0.0006 & 0.0001 & 0.0007 & 0.0011 \\
\hline GUATEMALA & 0.0194 & 0.0000 & 0.0003 & -0.0001 & 0.0003 & 0.0002 \\
\hline HONDURAS & 0.0265 & -0.0003 & 0.0001 & -0.0001 & 0.0000 & -0.0003 \\
\hline INDONESIA & 0.1176 & -0.0097 & 0.0074 & 0.0018 & 0.0092 & -0.0005 \\
\hline INDIA & 0.0389 & 0.0009 & 0.0339 & 0.0025 & 0.0363 & 0.0372 \\
\hline IRAN & 0.1324 & -0.0069 & 0.0018 & -0.0001 & 0.0017 & -0.0052 \\
\hline ICELAND & 0.0134 & -0.0001 & 0.0001 & 0.0000 & 0.0001 & 0.0000 \\
\hline ISRAEL & 0.0199 & -0.0006 & 0.0005 & 0.0001 & 0.0006 & 0.0000 \\
\hline JAMAICA & 0.0301 & -0.0002 & 0.0001 & 0.0000 & 0.0001 & -0.0001 \\
\hline JORDAN & 0.0263 & -0.0003 & 0.0001 & -0.0001 & -0.0001 & -0.0003 \\
\hline JAPAN & 0.2099 & 0.0215 & 0.0076 & -0.0070 & 0.0006 & 0.0221 \\
\hline KENYA & 0.0715 & -0.0023 & 0.0011 & -0.0001 & 0.0010 & -0.0013 \\
\hline KOREA REP. OF & 0.1900 & -0.0185 & 0.0021 & -0.0002 & 0.0019 & -0.0166 \\
\hline SRI LANKA & 0.0325 & -0.0005 & 0.0008 & -0.0002 & 0.0006 & 0.0000 \\
\hline MOROCCO & 0.0170 & -0.0001 & 0.0009 & -0.0002 & 0.0007 & 0.0006 \\
\hline MEXICO & 0.0648 & -0.0045 & 0.0038 & -0.0004 & 0.0034 & -0.0011 \\
\hline MALAYSIA & 0.0475 & -0.0030 & 0.0009 & -0.0002 & 0.0006 & -0.0024 \\
\hline NIGERIA & 0.2596 & -0.0152 & 0.0045 & 0.0000 & 0.0045 & -0.0107 \\
\hline NORWAY & 0.0482 & -0.0004 & 0.0003 & -0.0001 & 0.0003 & -0.0001 \\
\hline NEW ZELAND & 0.0175 & -0.0005 & 0.0004 & -0.0001 & 0.0003 & -0.0002 \\
\hline PAKISTAN & 0.0925 & -0.0025 & 0.0033 & 0.0000 & 0.0033 & 0.0007 \\
\hline
\end{tabular}




\begin{tabular}{|l|l|l|l|l|l|l|}
\hline PERU & 0.0468 & -0.0013 & 0.0018 & 0.0008 & 0.0026 & 0.0013 \\
\hline PHILIPPINES & 0.0498 & -0.0033 & 0.0026 & 0.0000 & 0.0026 & -0.0007 \\
\hline PARAGUAY & 0.0245 & -0.0004 & 0.0002 & -0.0003 & -0.0001 & -0.0005 \\
\hline SENEGAL & 0.0318 & -0.0008 & 0.0003 & -0.0004 & -0.0001 & -0.0009 \\
\hline EL SALVADOR & 0.0291 & 0.0002 & 0.0005 & 0.0007 & 0.0012 & 0.0013 \\
\hline SWEDEN & 0.0556 & 0.0005 & 0.0009 & 0.0000 & 0.0009 & 0.0014 \\
\hline SYRIA & 0.0432 & 0.0002 & 0.0008 & 0.0006 & 0.0014 & 0.0016 \\
\hline TOGO & 0.0288 & -0.0006 & 0.0001 & -0.0003 & -0.0002 & -0.0008 \\
\hline THAILAND & 0.1813 & -0.0094 & 0.0027 & 0.0000 & 0.0028 & -0.0066 \\
\hline TRINIDAD \& & & & & & & \\
TOBAGO & 0.0306 & -0.0004 & 0.0001 & 0.0000 & 0.0001 & -0.0003 \\
\hline TURKEY & 0.0346 & -0.0054 & 0.0029 & -0.0002 & 0.0027 & -0.0027 \\
\hline TANZANIA & 0.0921 & -0.0025 & 0.0010 & -0.0002 & 0.0009 & -0.0017 \\
\hline URUGUAY & 0.0223 & 0.0001 & 0.0002 & 0.0001 & 0.0003 & 0.0004 \\
\hline USA & 0.3049 & 0.0109 & 0.0296 & -0.0190 & 0.0106 & 0.0216 \\
\hline VENEZUELA & 0.0760 & -0.0029 & 0.0009 & 0.0000 & 0.0009 & -0.0020 \\
\hline SOUTH AFRICA & 0.0713 & -0.0005 & 0.0022 & 0.0001 & 0.0023 & 0.0018 \\
\hline Average & 0.065 & -0.001 & 0.003 & 0.000 & 0.002 & 0.001 \\
\hline
\end{tabular}

Note: INEFF: level of inefficiency, TD: technological diffusion (catch-up effect), EI: exogenous innovations, PII: energy price induced innovations, EI+PII: sum of exogenous and the induced innovations, and TC: technological change (TD+EI+PII) 